\title{
Erratum to clinicopathological models for predicting lymph node metastasis in patients with early-stage lung adenocarcinoma: the application of machine learning algorithms
}

\author{
Editorial Office \\ Journal of Thoracic Disease \\ Correspondence to: Editorial Office. Journal of Thoracic Disease. Email: jtd@amepc.org.
}

Submitted Aug 25, 2021. Accepted for publication Sep 01, 2021.

doi: $10.21037 /$ jtd-2021-38

View this article at: https://dx.doi.org/10.21037/jtd-2021-38

Erratum to: J Thorac Dis 2021;13:4033-42

In the article that appeared on Page: 4033-4042, Vol 13, No 7 (July 2021) Issue of the Fournal of Thoracic Disease (7TD) (1), there was an error in the order of the author affiliations. In this Correction, correct and incorrect versions are shown.

Incorrect: Yuming Chong ${ }^{1 \#} \wedge$, Yijun $\mathrm{Wu}^{2 \#}$, Jianghao Liu ${ }^{1 \#}$, Chang $\mathrm{Han}^{1}$, Liang Gong ${ }^{1}$, Xinyu Liu ${ }^{1}$, Naixin Liang ${ }^{3}$, Shanqing $\mathrm{Li}^{3}$

${ }^{1}$ Peking Union Medical College, Chinese Academy of Medical Sciences, Beijing, China; ${ }^{2}$ Department of Radiation Oncology, Peking Union Medical College Hospital, Chinese Academy of Medical Sciences \& Peking Union Medical College, Beijing, China; ${ }^{3}$ Department of Thoracic Surgery, Peking Union Medical College Hospital, Chinese Academy of Medical Sciences \& Peking Union Medical College, Beijing, China.

"These authors contributed equally to this work.

Correct: Yuming Chong ${ }^{1,2 \#}$, Yijun $\mathrm{Wu}^{1,2 \#}$, Jianghao Liu ${ }^{2 \#}$, Chang $\mathrm{Han}^{2}$, Liang Gong ${ }^{2}$, Xinyu Liu ${ }^{2}$, Naixin Liang ${ }^{1}$, Shanqing $\mathrm{Li}^{1}$

${ }^{1}$ Department of Thoracic Surgery, Peking Union Medical College Hospital, Chinese Academy of Medical Sciences \& Peking Union Medical College, Beijing, China; ${ }^{2}$ Peking Union Medical College, Chinese Academy of Medical Sciences, Beijing, China

\#These authors contributed equally to the work.

Click here to view the updated version of the article.

Open Access Statement: This is an Open Access article distributed in accordance with the Creative Commons AttributionNonCommercial-NoDerivs 4.0 International License (CC BY-NC-ND 4.0), which permits the non-commercial replication and distribution of the article with the strict proviso that no changes or edits are made and the original work is properly cited (including links to both the formal publication through the relevant DOI and the license). See: https://creativecommons.org/ licenses/by-nc-nd/4.0/. 


\section{References}

1. Chong Y, Wu Y, Liu J, et al. Clinicopathological models for predicting lymph node metastasis in patients with early-stage lung adenocarcinoma: the application of machine learning algorithms. J Thorac Dis 2021;13:4033-42.

Cite this article as: Editorial Office. Erratum to clinicopathological models for predicting lymph node metastasis in patients with early-stage lung adenocarcinoma: the application of machine learning algorithms. J Thorac Dis 2021;13(10):6205-6206. doi: 10.21037/jtd-2021-38 